\title{
Studies on sulfenamides. XVI. [1] New method of generating 2,4-dinitrobenzensulfenylnitrene using a microwave
}

\author{
Mitsuko Maeda, Yuki Takami and Takashi Michida* \\ Faculty of Pharmaceutical Sciences, Kobe-Gakuin University, Minatojima, chuo-ku, Kobe 650-8586, Japan
}

\begin{abstract}
2,4-Dinitrobenzenesulfenylnitrene was produced via the oxidation of 2,4-dinitrobenzensulfenamide with iodobenzene diacetate using microwave irradiation, and was trapped by various alkenes as an $\mathrm{N}$-sulfenylaziridine. However, $\beta$-methylstyrene gave 1 -phenyl-2,4-dinitrobenzenesulfenamides when it was used as nitrene trap.

The reaction was carried out in various solvents, with dichloromethane providing the best yield with a reaction time of only 30 min.

Conjugated double bonds acted as a nitrene trap and resulted in better yields than unconjugated bonds.
\end{abstract}

Molecular orbital calculation (PM3) revealed that a singlet nitrene reacted with a carbon-carbon double bond to give aziridines and that a biradical intermediate occurred in the reaction mechanism to produce the sulfenamide from $\beta$-methylstyrene.

\section{Introduction}

Although there have been many reports on nitrenes [1-10], little is known about sulfenylnitrenes [11-13], in part because there are few methods for generating these compounds. Sulfenylnitrenes have attracted our attention because of the chemical structure of their products (i.e., benzenesulfenamides with an aziridine skeleton). The 2-nitrobenzenesulfenyl or 2, 4-dinitrobenzenesulfenyl group is frequently used for protecting amino groups and can be easily removed with hydrogen chloride or reducing reagents [14-17]. Therefore, the reaction products of sulfenylnitrenes could be important intermediates in organic synthesis.

Recently, Yoshimura et al. reported a new method for generating sulfenylnitrenes from $\mathrm{N}$-sulfenylsulfodiimides in good yield [17]. However, the pioneering method developed by Atokinson is still attractive because the source of nitrene, 2, 4-dinitrobenzenesulfenamide (1), is easily obtained from commercially available compounds [18-20].

The typical method for generating sulfenylnitrenes has been the oxidation of 1 or $\mathrm{CF}_{3} \mathrm{SNH}_{2}$ with lead tetra acetate (LTA), which is a relatively strong oxidant [21]. However, in order to avoid oxidation of the reaction products, and to obtain good yields, milder oxidants must be used. For this purpose, oxidation of 1 with N-bromosuccinimide (NBS) was proposed in a previous paper [22]. Recent years have seen significant developments in the application of microwave technology in organic synthesis [23]; the aims of this paper were to use microwaves to oxidize 1 to establish a new method for generating 2,4-dinitrobenzenesulfenylnitrene and to used molecular orbital (MO) calculation to closely evaluate the reaction mechanism.

\section{Results and discussion}

Compound 1 in dichloromethane was oxidized with iodobenzene diacetate in the presence of styrene overnight at room temperature in order to evaluate the potential of iodobenzene diacetate as an oxidant. Although thin-layer chromatography showed the presence of $\mathbf{1}$ in the reaction solution, 1-(2,4-dinitrobenzenesulfenyl)-2-phenylaziridine (2) was obtained in $28 \%$ yield. Iodobenzene diacetate is thus able to oxidize 1, but only very slowly. Microwave irradiation was therefore used to accelerate this oxidation reaction. Dichloromethane containing $\mathbf{1}$ and styrene was placed in a tube with finely powdered potassium carbonate, iodobenzene diacetate was added to the tube, and then that was sealed with teflon film attached to an aluminum cap. The reaction was carried out in a single-mode cavity for $30 \mathrm{~min}$ with a 5 -min ramp time at $50^{\circ} \mathrm{C}$. Single-mode instruments produce one homogenous intense locus of energy that is highly reproducible. Due to their uniform energy distribution and high power density, these systems are typically most effective with small samples.

In order to optimize conditions, the reaction was carried out in various solvents. The temperature was adjusted to $10^{\circ} \mathrm{C}$ above the boiling point of the solvent; the results are summarized in Table 1.

Dichloromethane and chloroform gave relatively good results, but ethyl acetate gave a poor yield. Benzene, tetrahydrofuran and ethyl alcohol resulted in the production of unidentified compounds and the disappearance of compound $\mathbf{1}$. The best yield was obtained using dichloromethane as a solvent, and thus dichloromethane was used in subsequent reactions.

Correspondence to: Takashi Michida, Faculty of Pharmaceutical Sciences, KobeGakuin University, Minatojima, chuo-ku, Kobe 650-8586, Japan. Tel: 01081078974-1551.E-mail:michida@pharm.kobegakuin.ac.jp

Key words: nitrene, oxidation, microwave, aziridine, $P M 3$

Received: September 28, 2017; Accepted: October 23, 2017; Published: October 27,2017 
Table 1. Effects of solvent on yield of 1-(2,4-dinitrophenylsulfenyl)-2-phenylaziridine

\begin{tabular}{|c|c|}
\hline Solvent & Yield \\
\hline Benzene & $0 \%^{\mathrm{a})}$ \\
\hline Dichloromethane & $59 \%$ \\
\hline Chloroform & $48 \%$ \\
\hline Ethyl acetate & $11 \%$ \\
\hline Tetrahydrofurane & $0 \%$ a) \\
\hline Ethyl alcohol & $0 \%^{\mathrm{a})}$ \\
\hline
\end{tabular}

a) Unidentified compounds were obtained.

Various ratios of olefin to $\mathbf{1}$ were then examined, and the results are shown in Table 2.

Increasing the proportion of compound $\mathbf{1}$, which increased the generation of nitrene, did not improve the yield of compound 2 . However, increasing the amount of styrene improved the yield of compound 1.

Various olefins were used as nitrene traps, and the results are summarized in Table 3.

Conjugated olefins, such as stilbene, styrene and $\beta$-methylstyrene, gave good yields, but cyclooctene and cyclohexene, which have an unconjugated double bond, gave poor yields. $\alpha$-Methylstyrene gave 1-phenylvinyl-2,4-dinitrobenzenesulfenamide (3), while $\beta$-methystyrene provided 1-(2,4-dinitrobenzenesulfenyl)-2-methyl3 -phenylaziridine (4). Similar results were obtained in the reaction of 1 with NBS, while biradical intermediates shown in Chart 1 were postulated in a previous paper[13].

It is difficult to simulate all reactions, and thus the four reactions in Chart 2 were investigated.

Reactions 1 and 3 are the cyclo-addition of singlet nitrene and reactions 2 and 4 are the insertion of triplet nitrene into the $\mathrm{C}-\mathrm{H}$ bond of the methyl group. Our initial postulate is as follows: reaction 1 is slower than reaction 2 and reaction 3 is faster than reaction 4 .

A detailed comparison of the 4 reactions was then conducted by MO calculation, which was performed using HyperChem release 7.0 and a semi-empirical calculation (PM3) was applied to elucidate the reaction mechanism. Before the single point calculation, geometry optimization was performed using $\mathrm{MM}+$, followed by UHF (spin unrestricted Hartree-Fock) calculation with the Polak-Ribiere algorithm as the minimization algorithm until the total root-meansquare (RMS) gradient was reduced to $0.01 \mathrm{kcal} /(\AA \mathrm{mol})$.

The total energy of reactants and products in reactions 1 and 2, were estimated and the results are shown in Table 4.

The difference in total energy of singlet nitrene between triplet 1 is only $4 \mathrm{kcal} / \mathrm{mol}$, and the former is lower than the latter. The heat of reaction for 1-4, as estimated from Table 4, was 41,56, 40 and 57, respectively. The reaction between triplet nitrene and olefins is more favorable from the standpoint of the heat of reaction. These results cannot account for Table 3, as the actual reaction was reaction 3, not reaction 4

Activation energy $\left(\mathrm{E}_{\text {act }}=\mathrm{E}_{\text {trans }}\right.$ (sum of total energies of transition state) $-\mathrm{E}_{\text {react }}$ ) of reactions 3 and 4 was then estimated, and the former was found to be $14 \mathrm{kcal} / \mathrm{mol}$, while the latter was $12 \mathrm{kcal} / \mathrm{mol}$. Both reactions appear to proceed very rapidly, and reaction 4 is faster than reaction 3 , but the actual reaction is the latter. This suggests that the generated nitrene in this reaction system is in the singlet state.
Unfortunately, the calculation of the activation energy of the transition state of reactions 1 and 2 failed. The initial hypothesis was ruled out, and thus the existence of biradicals was proposed in reactions 2 and 4 , as shown in Chart 1.

The total energies of $\mathrm{A}$ and $\mathrm{B}$ are $-88035 \mathrm{kcal} / \mathrm{mol}$ and $-88029 \mathrm{kcal} /$ mol respectively, and former is comparable to that of aziridine.

Briefly, the values of total energy of products and reactants do not identify the problem. The migration of $\mathrm{H}$ in the methyl group in A to the $\mathrm{N}$ atom gives the sulfenamide, and in this case the activation energy is $44 \mathrm{kcal} / \mathrm{mol}$.

This supports the existence of a biradical in the reaction mechanism to give sulfenamide. Unfortunately, the transition states for the reactions from $A$ to 3 and $B$ to 3 could not be obtained, and thus clear conclusions could not be drawn. However, the existence of a biradical as the precursor of aziridine is not supported, as the direct insertion of singlet nitrene into the double bond of styrene is a very rapid reaction.

Table 2. Effects of molar ratio on yield of 1-(2,4,dinitrophenylsulfenyl)-2-phenylaziridine.

\begin{tabular}{|c|c|c|}
\hline Styrene & Sulfenamide & Yield \\
\hline 1 & 2 & $60 \%$ \\
\hline 1 & 1 & $59 \%$ \\
\hline 1.5 & 1 & $66 \%$ \\
\hline 2 & 1 & $72 \%$ \\
\hline 5 & 1 & $81 \%$ \\
\hline
\end{tabular}

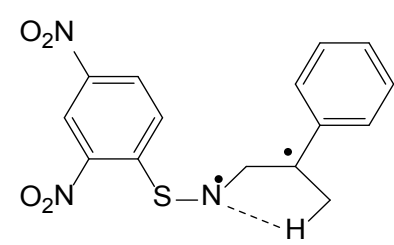

A

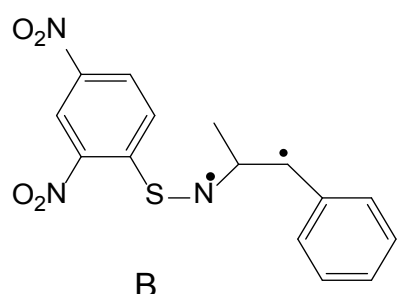

B
Chart 1

1)

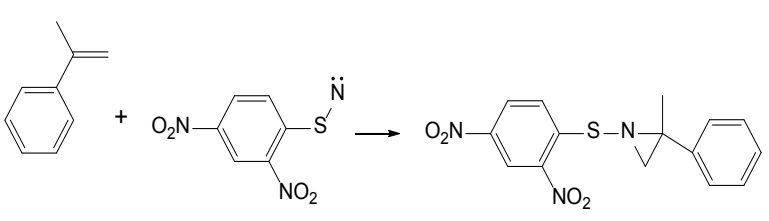

2)

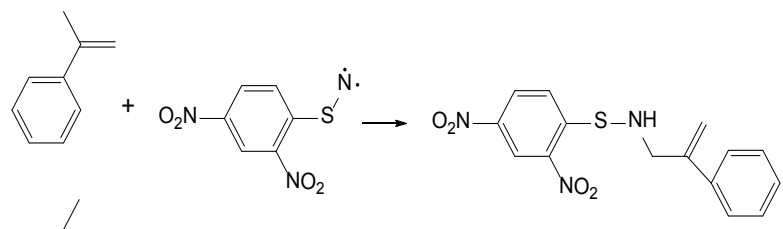

3)

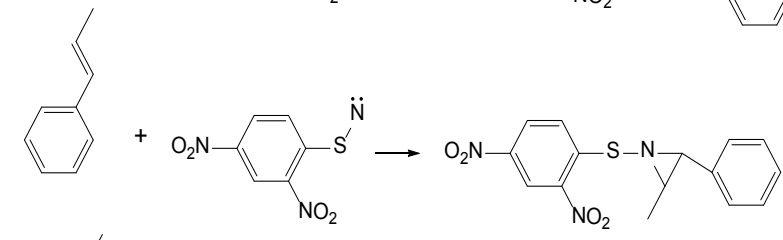

4)

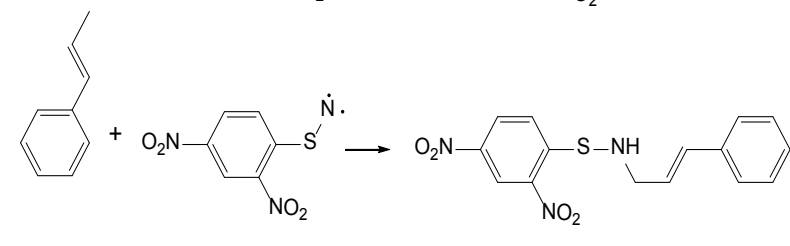

Chart 2 
Table 3. Results of olefin reaction with sulfenyl nitrene

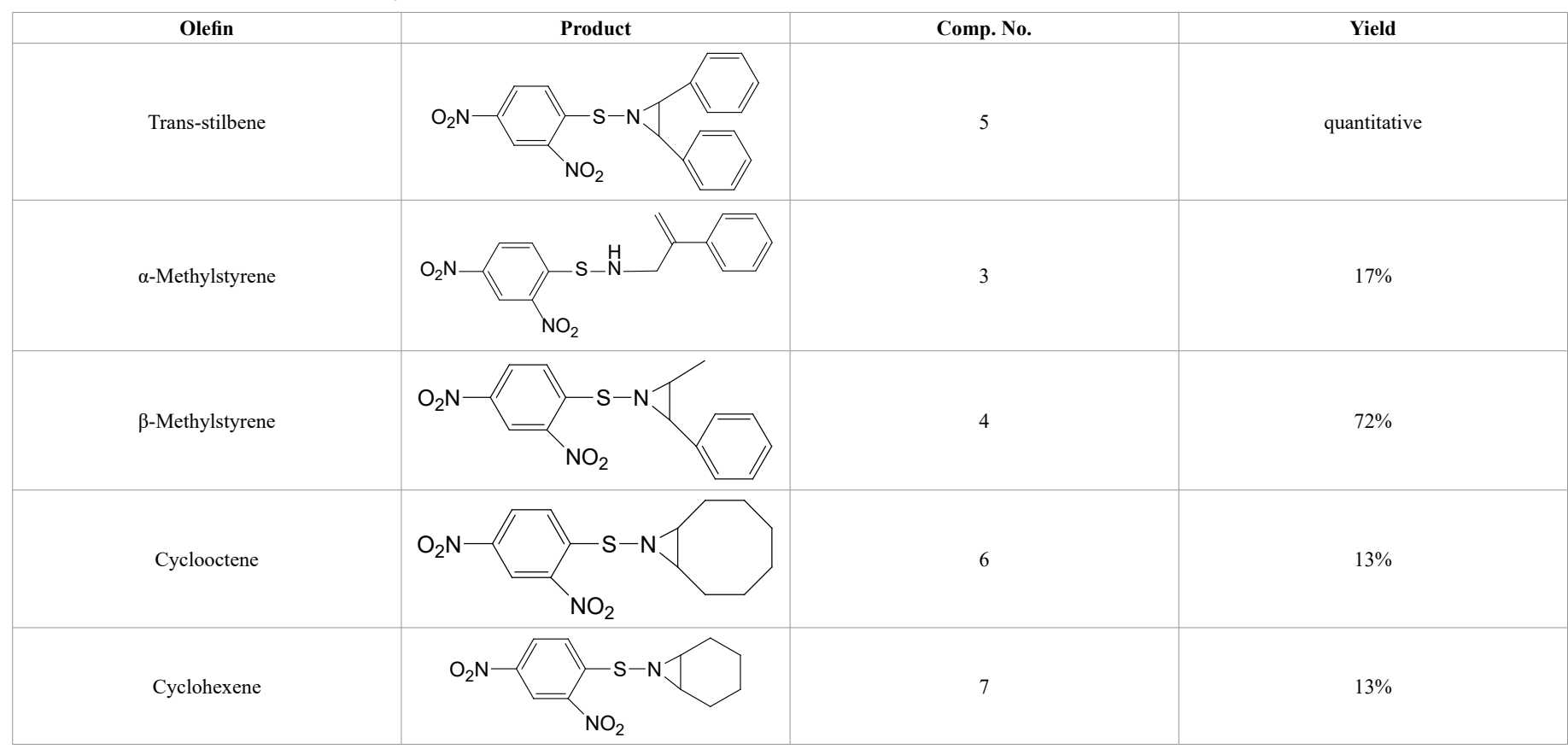

Table 4. Total energy of reactants and products of reactions 1 and 2.

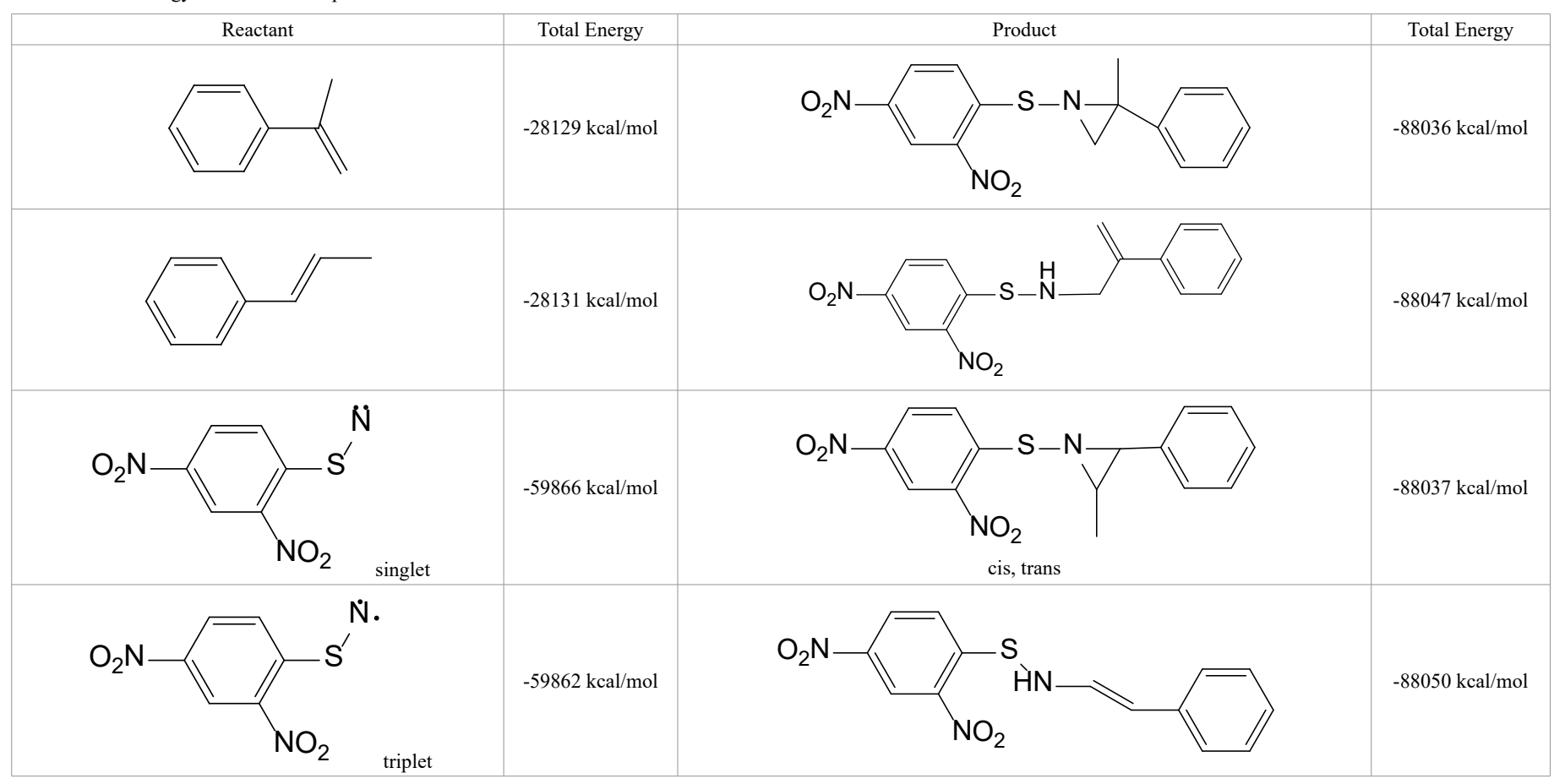

To confirm the existence of biradical in the mechanism, cis-stilbene was used as a nitrene trapper. If biradical intermediate exites, not only cis-1-(2,4-dinitrobenzenesulfenyl)-2,3- diphenylaziridine(8) but also compound 5 will be obtained. The reaction gave 8 (42\%) and $5(2.4 \%)$ as the products. Compound $\mathbf{5}$ was not so pure but too littile to purify further. Then the reaction mixture was analyzed with HPLC and the trace of 5 was detected.

The results do not contradict with the hypothesis but the yield of $\mathbf{5}$ is too small to support it.
Howevere biradical A must be the precursor of 3 , the more evidence is need to confirm.

\section{Experimental}

\section{Materials}

2,4-Dinitrobenzenesulfenamide was prepared as described previously [22]. All other reagents were purchased and used without further purification. 


\section{Apparatus}

A CEM discover (CEM co. USA) was used as the microwave generator. $\mathrm{MO}$ calculation was carried out using an Epson Direct Endeavor AT-900C (EPSON, Japan) personal computer running HyperChem release 7.0 (Hypercube Inc., Canada). NMR spectrum were obtained using BRUKER BIOSPIN DPX-400(Germany)

\section{Typical Example of Isolation of Products from the Reaction Mixture}

2,4-Dinitrobenesulfenamide (1, $0.34 \mathrm{~g})$, trans-stylene (1.42 g), $\mathrm{K}_{2} \mathrm{CO}_{3}(0.61 \mathrm{~g})$ and dichloromethane were placed in a tube and mixed. Then, iodobenzene diacetate $(0.51 \mathrm{~g})$ was added to the mixture and the tube was sealed with teflon film attached to an aluminum cap. The reaction was carried out in a single-mode cavity for $30 \mathrm{~min}$ with a 5-min ramp time at $50^{\circ} \mathrm{C}$. After cooling, the reaction mixture was loaded onto a silica gel column $(100 \mathrm{~g})$ with a hexane/ benzene $(1 / 1)$ as the mobile phase. The fraction containing compound 5 was concentrated and 0.62 $\mathrm{g}$ of $\mathbf{5}$ was obtained. The product was confirmed by direct comparison with an authentic sample [22]

trans-1-(2,4-Dinitrobenzenesulfenyl)-2,3-diphenylaziridine(5): ${ }^{1} \mathrm{H}-\mathrm{NMR}\left(\mathrm{CDCl}_{3}\right): 9.06(1 \mathrm{H}, \mathrm{d}, \mathrm{J}=2.35 \mathrm{~Hz}$, aromatic proton $), 8.54(1 \mathrm{H}$, $\mathrm{d}, \mathrm{J}=9.22 \mathrm{~Hz}$, aromatic proton), $8.38(1 \mathrm{H}, \mathrm{dd}, \mathrm{J}=2.41,9.18 \mathrm{~Hz}$, aromatic proton), 7.46-7.35 (10H, m, aromatic proton), $3.88(2 \mathrm{H}, \mathrm{s}, \mathrm{CH})$.

1-phenylvinyl-2,4-dinitrobenzenesulfenamide (3) : ${ }^{1} \mathrm{H}-\mathrm{NMR}(\mathrm{CD}-$ $\left.\mathrm{Cl}_{3}\right): 9.08(1 \mathrm{H}, \mathrm{d}, \quad \mathrm{J}=2.40 \mathrm{~Hz}$ aromatic proton),8.22(1H,dd, J=2.37, $9.12 \mathrm{~Hz}$,aromatic proton), $8.04(1 \mathrm{H}, \mathrm{d}, \mathrm{J}=9.06 \mathrm{~Hz}$, aromatic proton), 7.43 $7.36(5 \mathrm{H}, \mathrm{m}$, aromatic protons $), 5.48(1 \mathrm{H}, \mathrm{s}$, vinyl proton $), 5.32(1 \mathrm{H}, \mathrm{dd}$, $\mathrm{J}=0.90,2.02 \mathrm{~Hz}$, vinyl proton), $4.07\left(2 \mathrm{H}, \mathrm{dd}, \mathrm{J}=0.90,5.68 \mathrm{~Hz},-\mathrm{CH}_{2}^{-}\right)$, $2.94(1 \mathrm{H}, \mathrm{t}, \mathrm{J}=5.64 \mathrm{~Hz}, \mathrm{NH})$.

1-(2,4-dinitrobenzenesulfenyl)-2-methyl-3-phenylaziridine (4): ${ }^{1} \mathrm{H}-\mathrm{NMR}\left(\mathrm{CDCl}_{3}\right): 9.12(1 \mathrm{H}, \mathrm{d}, \mathrm{J}=2.07 \mathrm{~Hz}$, aromatic proton $), 8.37(1 \mathrm{H}, \mathrm{d}-$ $\mathrm{d}, \mathrm{J}=2.37,9.10 \mathrm{~Hz}$, aromatic proton), $7.47(1 \mathrm{H}, \mathrm{d}, \mathrm{J}=7.26 \mathrm{~Hz}$, aromatic proton), $7.35-7.23(4 \mathrm{H}, \mathrm{m}$, aromatic proton),3.76(1H,br, $\mathrm{CH})$ $3.53(1 \mathrm{H}, \mathrm{br}, \mathrm{CH}), 3.35(1 \mathrm{H}, \mathrm{d}, \mathrm{J}=17.85 \mathrm{~Hz}, \mathrm{CH} 2), 3.25(1 \mathrm{H}, \mathrm{dd}, \mathrm{J}=4.34,17.84$ $\mathrm{Hz}, \mathrm{CH} 2)$.

$\mathrm{N}$ - (2,4-dinitrobenzenesulfenyl) - 1,2-epiminocyclooc$\operatorname{tane}(6):{ }^{1} \mathrm{H}-\mathrm{NMR}\left(\mathrm{CDCl}_{3}\right): 9.13(1 \mathrm{H}, \mathrm{d}, \mathrm{J}=2.22 \mathrm{~Hz}$, aromastic proton $), 8.47(1 \mathrm{H}, \mathrm{d}, \mathrm{J}=9.36 \mathrm{~Hz}$, aromatic proton $), 8.42(1 \mathrm{H}, \mathrm{dd}, \mathrm{J}=2.26,9.1 \mathrm{~Hz}$, aromatic proton), 2.32-2.17 (4H, m, aliphatic protons), $1.71-1.35(10 \mathrm{H}$, $\mathrm{m}$, aliphatic proton).

$\mathrm{N}$-(2,4-dinitrobenzenesulfenyl)-1,2-epiminocyclopentane(7) ${ }^{1} \mathrm{H}-\mathrm{NMR}\left(\mathrm{CDCl}_{3}\right): 9.13(1 \mathrm{H}, \mathrm{d}, \mathrm{J}=2.22 \mathrm{~Hz}$, aromatic proton $), 8.47(1 \mathrm{H}, \mathrm{d}$, $\mathrm{J}=9.36 \mathrm{~Hz}$, aromatic proton), $8.42(1 \mathrm{H}, \mathrm{dd}, \mathrm{J}=2.26,9.1 \mathrm{~Hz}$, aromatic proton), $2.32-2.17(4 \mathrm{H}, \mathrm{m}$, aliphatic protons $), 1.71-1.35(10 \mathrm{H}, \mathrm{m}$, aliphatic proton). $10 / 23 / 2015$

\section{References}

1. Part XV, Michida T, Osawa E, Yamaoka T (1999) Studies on Sulfenamides. XV. SemiEmpirical Calculation of Reactivity of 4'-Substituted Benzenesulfenanilidyl Radicals. Chem Pharm Bull 47: 1787-1789.

2. Dehaen W, Becher J (1993) Ring-opening of five-membered heteroaromatic azides and nitrenes. Acta Chemica Scandinavica 47: 244-54.

3. Fuchigami T, NonakaT (1987) Electrochemical generation of reactive nitrogen species and their reactions. Studies in Organic Chemistry (Amsterdam) 30: 45-48.

4. Padwa A, Carlsen PHJ (1982) Nitrile ylides and nitrenes from $2 \mathrm{H}$-azirines. Reactive Intermediates (Plenum) 2: 55-119.

5. Wentrup C (1981) Carbenes and nitrenes in heterocyclic chemistry: intramolecular reactions. Advances in Heterocyclic Chemistry 28: 231-361.

6. Meth-Cohn O (1980) New approaches to heterocycles via nitrenes. Heterocycles 14 1497-1516.

7. Matlin SA (1979) Arynes, carbenes, nitrenes, and related species. Annual Reports Section B: Organic Chemistry 75: 79-95.

8. Lwowski W (1970) "Nitrenes" John Wiley and Sons, New York.

9. McManus SP (1973) Organic Reactive Intermediates, Academic Press, New York, 127-192.

10. Jones M, Moss RA (1981) Reactive Intermediates, Vol. 2, John Wiley and Sons, New York, 315-334.

11. Pihera P, Svoboda J (1997) Heterocyclic [3,2-b]-fused pentalenes and their benzoannellated derivatives. Chemicke Listy 91: 547-557.

12. Mayer R, Decker D, Bleisch S, Domschke G (1987) Attempts to synthesize sterically hindered thiazyl arenes and their relationship to arylsulfenyl nitrenes. Journal fuer Praktische Chemie 329:81-6.

13. Chaudri, Tanweer A (1979) Oxidation of sulfonamides. Pakistan Journal of Scientific and Industrial Research 19: 115-17.

14. Kobayashi T, Ino K, Hiraoka T (1977) A novel synthetic rout to 7 alphamethoxycephalosporins. J Am Chem Soc 99: 5505-5507. [Crossref]

15. Zervas L, Borovas D, Gazis E (1963) New methods in peptide synthesis. I Tritylsulfenyl and o-nitrophenylsulfenyl groups as N-protecting groups. $\mathrm{J} \mathrm{Am} \mathrm{Chem}$ Soc 85: 3660-3666.

16. Kessler W, Iselin B (1966) Selective cleavage of substituted phenylsulfenyl protective groups in peptide syntheses. Helv Chim Acta 49: 1330-1344.

17. Yoshimura T, Fujiie T, Fujii T (2007) Moderate generation of sulfenylnitrenes from novel N-sulfenylsulfodiimides. Tetrahedron Letter 48: 427-430.

18. Atokinson RS, Judkins BD (1979) 2,4-Dinitrobenzenesulfenylnitrene as a reactive intermediate. $J$ Chem Soc Chem Comm 833-835.

19. Atokinson RS, Judkins BD (1979) Oxidation of 2,4-dinitrobenzenesulfenamide in the presence of alkenes: formation of aziridines. J Chem Soc Chem Comm 832-833.

20. Atokinson RS, Judkins BD, Khan N (1982) (2,4-Dinitrophenyl)sulfenylnitrene: addition to (Z)- and (E)-1-phenylpropene. J Chem Soc Perkin Trans I 2491-2497.

21. Atokinson RS, Judkins BD (1981) Intermolecular trapping of sulfenylnitrenes by alkenes. J Chem Soc Perkin Trans I 2615-2619.

22. Michida T, Sayo H (1994) Studies on sulfenamides. XIV. A new method of generating of 2,4-dinitrobenzenesulfenylnitrene. Chem Pharm Bull 42: 27-30.

23. See the following book and references cited therein: Hayes BL, "Microwave Synthesis Chemistry at the Speed of Light" CEM Publishing, Matthews, 2002.

Copyright: (C2017 Maeda M. This is an open-access article distributed under the terms of the Creative Commons Attribution License, which permits unrestricted use, distribution, and reproduction in any medium, provided the original author and source are credited. 